NASA/CR-2002-211940

ICASE Report No. 2002-36

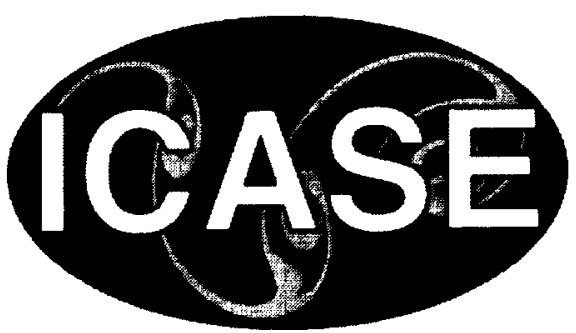

\title{
Polymer-single Wall Carbon Nanotube Composites for Potential Spacecraft Applications
}

C. Park, Z. Ounaies, and K.A. Watson

ICASE, Hampton, Virginia

K. Pawlowski, S.E. Lowther, J.W. Connell, E.J. Siochi,

J.S. Harrison, and T.L. St. Clair

NASA Langley Research Center, Hampton, Virginia 


\section{The NASA STI Program Office ... in Profile}

Since its founding, NASA has been dedicated to the advancement of aeronautics and space science. The NASA Scientific and Technical Information (STI) Program Office plays a key part in helping NASA maintain this important role.

The NASA STI Program Office is operated by Langley Research Center, the lead center for NASA's scientific and technical information. The NASA STI Program Office provides access to the NASA STI Database, the largest collection of aeronautical and space science STI in the world. The Program Office is also NASA's institutional mechanism for disseminating the results of its research and development activities. These results are published by NASA in the NASA STI Report Series, which includes the following report types:

- TECHNICAL PUBLICATION. Reports of completed research or a major significant phase of research that present the results of NASA programs and include extensive data or theoretical analysis. Includes compilations of significant scientific and technical data and information deemed to be of continuing reference value. NASA's counterpart of peer-reviewed formal professional papers, but having less stringent limitations on manuscript length and extent of graphic presentations.

- TECHNICAL MEMORANDUM. Scientific and technical findings that are preliminary or of specialized interest, e.g., quick release reports, working papers, and bibliographies that contain minimal annotation. Does not contain extensive analysis.

- CONTRACTOR REPORT. Scientific and technical findings by NASA-sponsored contractors and grantees.
- CONFERENCE PUBLICATIONS. Collected papers from scientific and technical conferences, symposia, seminars, or other meetings sponsored or cosponsored by NASA.

- SPECIAL PUBLICATION. Scientific, technical, or historical information from NASA programs, projects, and missions, often concerned with subjects having substantial public interest.

- TECHNICAL TRANSLATION. Englishlanguage translations of foreign scientific and technical material pertinent to NASA's mission.

Specialized services that complement the STI Program Office's diverse offerings include creating custom thesauri, building customized data bases, organizing and publishing research results ... even providing videos.

For more information about the NASA STI Program Office, see the following:

- Access the NASA STI Program Home Page at http://www.sti.nasa.gov

- Email your question via the Internet to help@sti.nasa.gov

- Fax your question to the NASA STI Help Desk at (301) 621-0134

- Telephone the NASA STI Help Desk at (301) 621-0390

- Write to: NASA STI Help Desk NASA Center for AeroSpace Information 7121 Standard Drive Hanover, MD 21076-1320 
NASA/CR-2002-211940

ICASE Report No. 2002-36

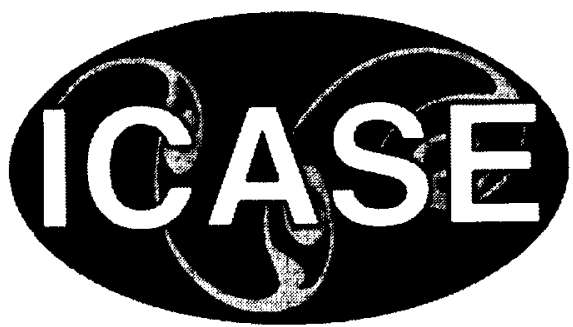

\section{Polymer-single Wall Carbon Nanotube Composites for Potential Spacecraft Applications}

C. Park, Z. Ounaies, and K.A. Watson

ICASE, Hampton, Virginia

K. Pawlowski, S.E. Lowther, J.W. Connell, E.J. Siochi,

J.S. Harrison, and T.L. St. Clair

NASA Langley Research Center, Hampton, Virginia

ICASE

NASA Langley Research Center

Hampton, Virginia

Operated by Universities Space Research Association 
Available from the following:

NASA Center for AeroSpace Information (CASI)

7121 Standard Drive

Hanover, MD 21076-1320

(301) $621-0390$
National Technical Information Service (NTIS) 5285 Port Royal Road

Springfield, VA 22161-2171

(703) 487-4650 


\title{
POLYMER-SINGLE WALL CARBON NANOTUBE COMPOSITES FOR POTENTIAL SPACECRAFT APPLICATIONS
}

\author{
C. PARK ${ }^{1}$, Z. OUNAIES ${ }^{\prime}$, K. A. WATSON', K. PAWLOWSKI ${ }^{2}$, S. E. LOWTHER ${ }^{2}$, J. W. CONNELL ${ }^{2}$, \\ E. J. SIOCHI ${ }^{2}$, J. S. HARRISON ${ }^{2}$, AND T. L. ST. CLAIR ${ }^{2}$
}

\begin{abstract}
Polymer-single wall carbon nanotube (SWNT) composite films were prepared and characterized as part of an effort to develop polymeric materials with improved combinations of properties for potential use on future spacecraft. Next generation spacecraft will require ultra-lightweight materials that possess specific and unique combinations of properties such as radiation and atomic oxygen resistance, low solar absorptivity, high thermal emissitivity, electrical conductivity, tear resistance, ability to be folded and seamed, and good mechanical properties. The objective of this work is to incorporate sufficient electrical conductivity into space durable polyimides to mitigate static charge build-up. The challenge is to obtain this level of conductivity $\left(10^{-8} \mathrm{~S} / \mathrm{cm}\right)$ without degrading other properties of importance, particularly optical transparency. Several different approaches were attempted to fully disperse the SWNTs into the polymer matrix. These included high shear mixing, sonication, and synthesizing the polymers in the presence of pre-dispersed SWNTs. Acceptable levels of conductivity were obtained at loading levels less than one tenth weight percent SWNT without significantly sacrificing optical properties. Characterization of the nanocomposite films and the effect of SWNT concentration and dispersion on the conductivity, solar absorptivity, thermal emissivity, mechanical and thermal properties were discussed. Fibers and non-woven porous mats of SWNT reinforced polymer nanocomposite were produced using electrospinning.
\end{abstract}

Key words. single wall carbon nanotubes, composites, dispersion, conductivity

Subject classification. Structures and Materials

1. Introduction. This study proposes an approach to design a durable, ultra-lightweight structure using single wall carbon nanotubes in a polymer matrix that possess a unique combination of properties required for long-term performance in aerospace applications. These novel nanocomposites will be designed to provide the following features; ultra-lightweight, chemical stability, high thermal and electrical conductivity, low permeability, hydrolytic oxidation resistance, radiation resistance, atomic oxygen resistance, low solar absorption, high emissivity, low coefficient of thermal expansion, and mechanical durability.

Carbon nanotubes have attracted tremendous attention since their discovery [1] due to their unique electronic and mechanical properties [2]. These superb intrinsic properties are most likely to be expected in SWNT, rather than in MWNT because of its flawless structure and low density $\left(1.33-1.40 \mathrm{~g} / \mathrm{cm}^{3}\right)$. There is a great deal of interest in aerospace and electronics applications involving high temperature polymers (e.g. polyimides), and significant benefits in strength and electrical properties are expected from SWNT reinforcement. SWNTs, however, have been rarely used as reinforcing inclusions in a polymer matrix mainly because of the difficulty in efficient dispersion. This difficulty arises from the non-reactive surface character of SWNT.

1 ICASE, MS 132C, NASA Langley Research Center, Hampton, VA 23681. This research was supported by the National Aeronautics and Space Administration under NASA Contract No. NAS1-97046 while the first three authors were in residence at ICASE, NASA Langley Research Center, Hampton, VA 23681.

${ }^{2}$ Advanced Materials and Processing Branch, MS 226, NASA Langley Research Center, Hampton, VA 23681. 
Most dispersion studies have been directed toward chemical modification of the SWNT surface. Although many researchers have attempted to functionalize nanotube ends and exterior walls with various routes, the solubility of these derivatized tubes is minimal and inefficient [3-5]. Recently, in situ polymerization under sonication methods enabled efficient coating of MWNT with a conductive polymer [6] and homogeneous dispersion of SWNT in an aromatic polymer [7]. This method along with a judicious selection of a polymer matrix enabled homogeneously dispersing SWNT into a polymer matrix on a nanometer scale at low loadings $(\leq 1.0 \mathrm{vol} \%)$ [ 7$]$.

In this study, a method to develop a nanocomposite containing a well-dispersed SWNT inclusion and characterization results of the resultant nanocomposites are presented.

2. Experimental. Purified laser ablated single wall carbon nanotubes (SWNTs) were purchased from Rice University. These SWNTs were about $1.2-1.6 \mathrm{~nm}$ in diameter and $3 \mu \mathrm{m}$ long. The polymer used as a matrix was a colorless polyimide (CP2) [8]. Diamine and dianhydride used to synthesize CP2 were 1,3-bis(3-aminophenoxy) benzene (APB) and 2,2-bis(3,4-anhydrodicarboxyphenyl) hexafluoropropane (6FDA), respectively. The diamine (APB) was purchased from Mitsui-Toatsu and used as received. The dianhydride (6FDA) was purchased from Imitec and used after sublimation. Asreceived anhydrous dimethyl formamide (DMF, Fisher) was used as a solvent.

A dilute SWNT solution, typically around $0.05 w t \%$ in DMF, was prepared by homogenizing for 10 min and sonicating for one and a half hours $(47 \mathrm{kHz})$. The pre-dispersed SWNT solution was used as a solvent for the polyamic acid synthesis with the diamine and dianhydride. The entire reaction was carried out with stirring in a nitrogen-purged flask immersed in a $40 \mathrm{kHz}$ ultrasonic bath until the solution viscosity increased and stabilized. At this point, additional stirring was continued for several hours to form a SWNT-Polyamic acid solution without further sonication. Acetic anhydride and pyridine were used as catalysts to chemically imidize the SWNT-Polyamic acid.

A series of SWNT/CP2 nanocomposite films were prepared with SWNT concentrations ranging from 0.01 to $1.0 \mathrm{vol} \%$. As a control sample, a nanocomposite film (1.0vol\%) was prepared by direct mixing of the pre-dispersed SWNT solution with a pure CP2 polyimide solution by stirring. The SWNT/CP2 solutions prepared were cast and dried in a dry air-flowing chamber. Subsequently, the dried tack-free films were cured at $110,170,210$, and $250^{\circ} \mathrm{C}$ for an hour each in an oven to obtain solvent-free freestanding films. DC conductivity and current-voltage measurements were performed with a Keithley resistivity test fixture Model 8009 interfaced with a Keithley electrometer/high resistance meter Model 6517 according to ASTM D257. AC volume conductivity was measured using a Hewlett Packard precision LCR meter Model 4284, frequency range $20 \mathrm{~Hz}-1 \mathrm{MHz}$. The AC conductivity was calculated from the measured admittance modulus $|Y|$ and phase $\theta$ where,

$$
Y=\frac{1}{R}+j 2 \pi f C
$$

$R$ is the resistance, $C$ is the capacitance and $f$ is the frequency of measurement.

The conductivity $\sigma$ is then expressed as,

$$
\sigma=|Y| \cos \theta \frac{t}{A}
$$

$t$ and $A$ are the thickness and area of the film, respectively. Optical properties of these films were evaluated by examining transmission at 500nm with Perkin Elmer Lambda 900 UV/Vis/NIR 
spectrophotometer. Solar absorptivities were measured on an Aztek Model LPSR-300 spectroreflectometer with measurements taken between 0.25 to $2.8 \mu \mathrm{m}$ with a vapor deposited aluminum on Kapton ${ }^{\circledR}$ film as a reflective reference according to ASTM E903-82. An Aztek Temp 2000A infrared reflectometer was used to measure thermal emissivity. Mechanical properties of the films were evaluated by a dynamic mechanical thermal analyzer (DMA, Rheometric Scientific). Thermal stability was investigated by dynamic thermogravimetric analysis (TGA, Seiko) at a heating rate of $2.5^{\circ} \mathrm{C} / \mathrm{min}$ in air. Fibers and non-woven mats of the SWNT-Polyimide solutions were prepared by electrospinning using a DC electric field ranging from $150-200 \mathrm{kV} / \mathrm{m}$. JEOL JSM-5600 scanning electron microscope (SEM) was used to examine the electrospun fibers.

TABI.F. 1

Optical and thermal properties of SWNT/CP2 nanocomposite films.

\begin{tabular}{|c|c|c|c|c|}
\hline $\begin{array}{c}\text { SWNT conc. } \\
(\mathrm{vol} \%)\end{array}$ & $\begin{array}{c}\text { Transmission at } \\
500 \mathrm{~nm}(\%)\end{array}$ & $\begin{array}{c}\text { Temp }\left({ }^{\circ} \mathrm{C}\right) \text { at } \\
5 \mathrm{wt} \% \text { loss }\end{array}$ & $\begin{array}{c}\text { Solar } \\
\text { absorptivity }(\alpha)\end{array}$ & $\begin{array}{c}\text { Thermal } \\
\text { emissivity }(\varepsilon)\end{array}$ \\
\hline $\mathrm{CP} 2$ & 85 & 444 & 0.068 & 0.525 \\
\hline 0.1 & 68 & 461 & 0.268 & 0.578 \\
\hline 0.2 & 62 & 474 & 0.398 & 0.614 \\
\hline 0.5 & 54 & 481 & 0.362 & 0.620 \\
\hline 1.0 & 32 & 479 & 0.478 & 0.652 \\
\hline $1.0^{*}$ & $<1$ & $\mathrm{~N} / \mathrm{A}$ & $\mathrm{N} / \mathrm{A}$ & 0.735 \\
\hline
\end{tabular}

Films were prepared by in situ polymerization under sonication except *(direct mixing).

3. Results and Discussion. SWNT reinforced polyimide nanocomposites were synthesized by in situ polymerization of monomers of interest in the presence of sonication. Scanning probe, transmission electron microscopy revealed that dispersion of SWNT was uniform through the matrix on a nanometer scale although some agglomerates of SWNT bundles remained on a micrometer scale [7,9]. Most of SWNTs were dispersed as bundles, but their thickness decreased noticeably compared to as-received SWNT bundles. This uniform dispersion of SWNTs provided efficient reinforcing (electrical, mechanical, thermal) effects on the polymer matrix without sacrificing the optical properties significantly. Figure 1(a) shows DC conductivity of SWNT/CP2 nanocomposite films as a function of SWNT concentration. The pure CP2 polyimide exhibited volume conductivity around $6 \times 10^{-18} \mathrm{~S} / \mathrm{cm}$, and incorporation of SWNT in the polyimide increased the conductivity more than 10 orders of magnitude at very low SWNT loading. A sharp increase was observed between 0.02 and $0.1 \mathrm{vol} \%$, and then the conductivity increased moderately at loading levels in excess of $0.1 \mathrm{vol} \%$. This behavior indicates that a percolation threshold of the nanocomposites resides between 0.02 and 0.1 vol\%.

Percolation theory dictates that above the threshold, a conductive path appears and the material behaves as a conductor. It also dictates a power law relationship between the conductivity of the composite and the variable $\left(v-v_{c}\right)$, where $v$ is the weight ratio of the SWNT and $v_{c}$ is the weight ratio at the threshold. The inset of Figure 1(a) demonstrates that this is the case assuming $v_{c}=0.05 \mathrm{vol} \%$. The conductivity of the composite is linear with respect to $\left(v-v_{c}\right)$ in a logarithmic scale, and the relationship is given by,

$$
\sigma=10^{-6}\left(v-v_{c}\right)^{1.5}
$$




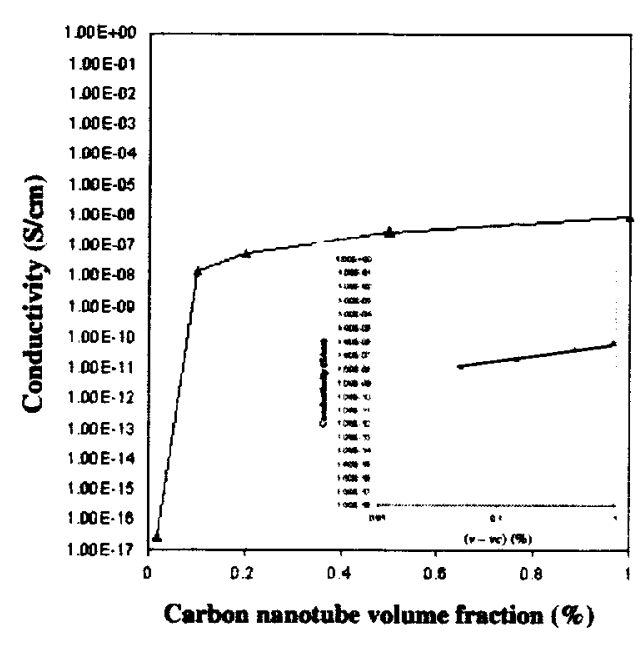

(a)

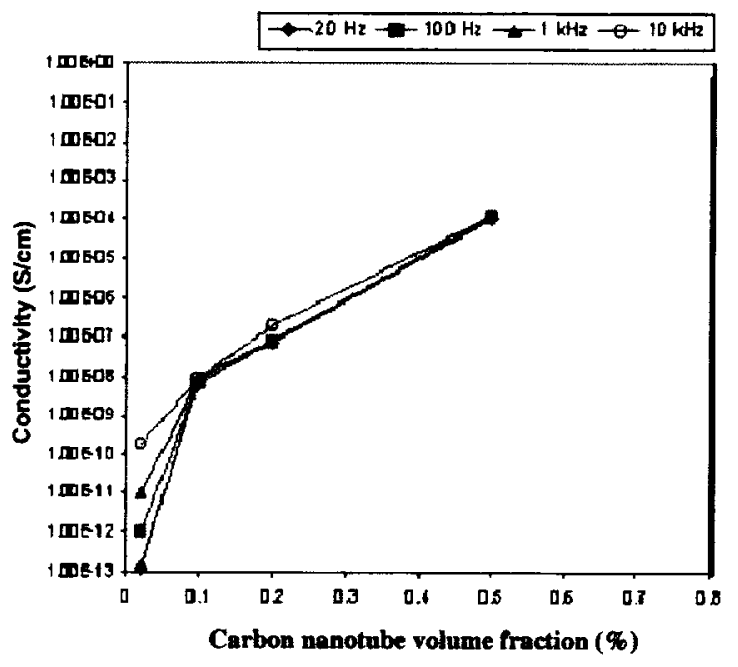

(b)

FIG. 1. (a) DC conductivity, inset is the percolation equation fitting, (b) AC conductivity of SWNT/CP2 nanocomposites.

Some preliminary results on I-V measurements revealed that the SWNT/CP2 nanocomposites exhibited a non-ohmic behavior as the conduction mechanism. It is most likely that a quantum tunneling conduction (electron hopping) occurs as a SWNT loading surpassed the percolation threshold. Figure 1(b) shows AC conductivity of the nanocomposites as a function of SWNT loading and frequency. The AC conductivity results were consistent with the DC results, which show the same trend of conductivity and percolation threshold with respect to increasing SWNT loading. It is noted that at $0.02 \mathrm{vol} \%$, the conductivity shows a strong dependence on frequency, where the conductivity increased with increasing frequency. On the other hand, for 0.1 vol\% and higher, the frequency dependence disappeared. This shows that SWNT/CP2 nanocomposites behaved as a capacitor below the percolation threshold and as a conductor above the threshold. The level of the percolation threshold of this SWNT/CP2 nanocomposite was an order of magnitude lower than that of conventional carbon fiber reinforced polymer composites.

The optical properties were evaluated by monitoring the intensity of transmitted light illuminated at $500 \mathrm{~nm}$ wavelength through the films (normalized at $34 \mu \mathrm{m}$ thick) and shown in Table 1 . This frequency was chosen since spacecraft experiences highest solar radiation at this frequency from black bodies. At 0.1 vol $\%$ SWNT loading, $68 \%$ light was able to transmit and $54 \%$ light transmission was observed at $0.5 \mathrm{vol} \%$ SWNT loading. At $1.0 \mathrm{vol} \%$ SWNT loading, 32\% light transmitted through the nanocomposite films synthesized by in situ polymerization under sonicaiton while less than $1 \%$ light transmitted through those prepared by the simple direct mixing method. Uniform dispersion of SWNT in the polymer matrix is crucial to achieve high conductivity at low SWNT loadings without significant detraction of the optical transparency. Absorbance of light of a SWNT/CP2 film at $500 \mathrm{~nm}$ increased linearly with increasing thickness with the correlation coefficient equal to 0.993 , which is another indication of uniform dispersion of SWNT in the polymer matrix. At about 0.1 vol\% SWNT loading, the nanocomposite films exhibited sufficient conductivity to mitigate electrostatic charges $\left(10^{-8} \mathrm{~S} / \mathrm{cm}\right)$ with reasonable optical transparency $(68 \%)$.

Solar absorptivity $(\alpha)$ and thermal emissivity $(\varepsilon)$ are important criteria for space applications. For many applications, low $\alpha$, high $\varepsilon$, and low ratio of $\alpha / \varepsilon$ are desirable. These measurements of the SWNT/CP2 films are shown in Table 1. Both $\alpha$ and $\varepsilon$ increased with increasing SWNT concentration. Although incorporation of 0.1 vol\% SWNT in the polymer showed a factor of four increase in solar 
absorptivity, the value remained low enough for many space applications. The ratio of the solar absorptivity to the thermal emissivity was about 0.46 , which is slightly lower than the desirable ratio for next generation space telescope outermost sunshield layer $(0.5)$.

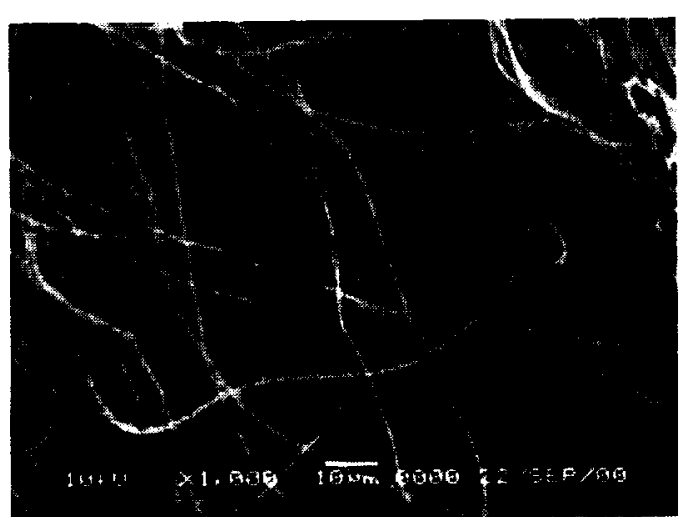

(a)

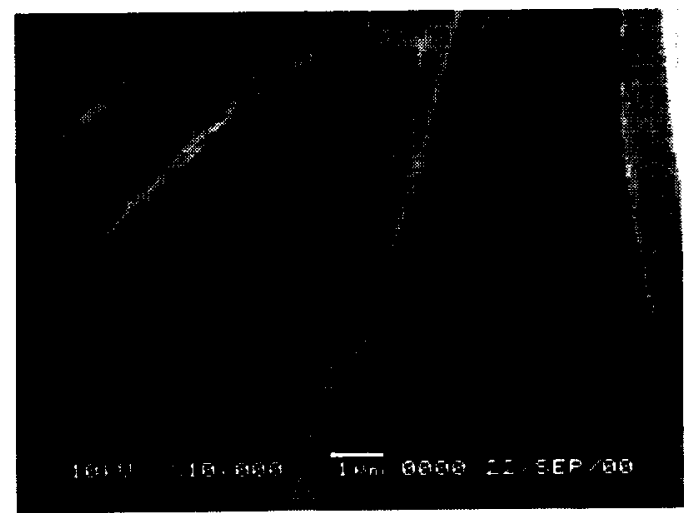

(b)

FIG. 2. Scanning electron micrographs of electrospun fibers of SWNT/CP2.

Mechanical properties of the SWNT/CP2 nanocomposite films were measured dynamically. Storage modulus of the nanocomposites increased linearly with increasing SWNT concentration and $65 \%$ increase was achieved at $1.0 \mathrm{vol} \%$ SWNT loading. The loss spectra revealed that broad dissipation peak of the pristine polymer spectrum below $\mathrm{T}_{\mathrm{g}}$ disappeared with the incorporation of SWNT, which implies that SWNT reinforcement made the composite more elastic. In addition, the $\tan \delta$ maximum upshifted by $10^{\circ} \mathrm{C}$ at 1.0 vol $\%$ SWNT with reduced loss peak compared to the pristine $\mathrm{CP} 2$ polyimide film.

Dynamic thermal stability was assessed with TGA by monitoring temperatures at $5 \mathrm{wt} \%$ loss. Table 1 shows that the temperature at $5 \mathrm{wt} \%$ loss increased with increasing SWNT concentration. A $35^{\circ} \mathrm{C}$ increase was observed at $0.5 \mathrm{wt} \% \mathrm{SWNT}$. This improved thermal stability conjunction with increased thermal emissivity indicates that uniformly dispersed SWNT provided its superior thermo-oxidative stability and thermal conductivity throughout the polymer matrix efficiently at very low SWNT loadings.

SWNT/CP2 nanocomposite solution was successfully spun using a DC electric field to form continuous fibers. Figure 2 shows 0.1 vol\% SWNT/CP2 nanocomposite fibers spun by electrospinning. The diameter of the eletrospun fibers ranged from $500 \mathrm{~nm}$ to $2 \mu \mathrm{m}$. These fibers can be collected as various forms including non-woven porous mats in a three-dimensional shape and isolated single fibers. The spun fibers are expected to have aligned SWNT or bundles along the fiber direction due to combination of dielectrophoretic forces caused by dielectric or conductivity mismatch between SWNT and the polymer solution and high shear forces induced by the spinning. Electrical, mechanical, and thermal properties of the aligned SWNT reinforced polymer fibers can be tailored by controlling the SWNT loadings for specific space applications.

4. Conclusions. Uniformly dispersed SWNT reinforced polyimide nanocomposites were developed for potential space applications. The resultant nanocomposites exhibit a unique combination of properties, including low color in thin films, high optical transparency, electrical conductivity sufficient to mitigate static charge build-up, low solar absorptivity, high thermal emissivity, high stiffness and strength, and high thermal stability. These lightweight nanocomposites are useful in a variety of aerospace applications, primarily because of their combination of electrical conductivity and high optical transmission. Examples of the space applications include thin film membranes on antennas, secondsurface mirrors, thermal optical coatings, and multi-layer thermal insulation (MLI) blanket materials, and 
low areal density solar sail membranes. These materials can be processed into various material forms such as thin films, fibers, foams, threads, adhesive film, coatings, dry powders, and fiber coated prepreg.

Acknowledgements. Authors would like to thank Crystal Topping for experimental support.

\section{REFERENCES}

[1] S. IIJIMA, Helical Microtubules of Graphitic Carbon, Nature, 354 (1991), pp. 56-58.

[2] P.M. AJAYAN, Nanotubes from Carbon, Chemical Reviews, 99 (1999), pp. 1787-1799.

[3] J. Chen, M.A. Hamon, H. Hu, Y. Chen, A.M. Rao, P.C. Eklund, And R.C. Haddon, Solution Properties of Single-Walled Carbon Nanotubes, Science, 282 (1998), pp. 95-98.

[4] E.T. MiCKelson C.B. HuffMAN, A.G. RinZleR, R.E. SMALley, R.H. HAUGE, AND J.L. MARGRAVE, Fluorination of Single-Wall Carbon Nanotubes, Chemical Physics Letters, 296 (1998), pp. 188-194.

[5] J.L. BAHR AND J. TOUR, Highly Functionalized Carbon Nanotubes Using In Situ Generated Diazonium Compounds, Chemistry of Materials, 13 (2001), pp. 3823-3824.

[6] J. FAN, M. WAN, D. ZhU, B. Chang, Z. PAN, AND S. XIE, Synthesis, Characterizations, and Physical Properties of Carbon Nanotubes Coated by Conducting Polypyrrole, Journal of Applied Polymer Science, 74 (1999), pp. 2605-2610.

[7] C. Park, Z. Ounaies, K.A.WATSON, R.E.Crooks, S.E. Lowther, J.W. ConNEll, E.J. Siochi, J.S. HARRISON, AND T.L. ST.ClaIR, Dispersion of Single Wall Carbon Nanotubes by In Situ Polymerization Under Sonication, Chemical Physics Letters, 364 (2002), pp. 303-308.

[8] A.K. ST. Clair, T.L. ST. CLAIR, AND W.S. SLEMP, Proceeding of the $2^{\text {nd }}$ International Conference on Polyimides, ed. W. Weber and M. Gupta, Society of Plastics Engineers (1987), pp. 16-36.

[9] P.T. LILlEHEI, C. PARK, J.H. RouSE, AND E.J. SIOCHI, Imaging carbon Nanotubes in High Performance Polymer Composites via Magnetic Force Microscopy, Nano Letters, 2 (2002), pp. 827-829. 


\begin{tabular}{|c|c|c|c|}
\hline \multicolumn{3}{|c|}{ REPORT DOCUMENTATION PAGE } & $\begin{array}{l}\text { Form Approved } \\
\text { OMB No. 0704-0188 }\end{array}$ \\
\hline \multicolumn{4}{|c|}{ 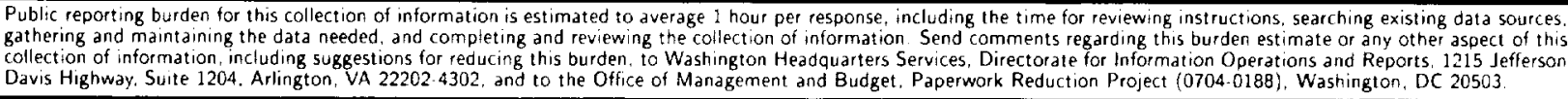 } \\
\hline 1. AGENCY USE ONLY(Leave blank) & $\begin{array}{l}\text { 2. REPORT DATE } \\
\text { October } 2002\end{array}$ & \multicolumn{2}{|c|}{$\begin{array}{l}\text { 3. REPORT TYPE AND DATES COVERED } \\
\text { Contractor Report }\end{array}$} \\
\hline \multicolumn{3}{|c|}{$\begin{array}{l}\text { 4. TITLE AND SUBTITLE } \\
\text { POLYMER-SINGLE WALL CARBON NANOTLBE } \\
\text { COMPOSITES FOR POTENTIAL SPACECRAFT APPLICATIONS }\end{array}$} & \multirow[t]{2}{*}{$\begin{array}{l}\text { 5. FUNDING NUMBERS } \\
\text { C NAS1-97046 } \\
\text { WU } 505-90-52-() 1\end{array}$} \\
\hline \multicolumn{3}{|c|}{$\begin{array}{l}\text { 6. AUTHOR(S) } \\
\text { C. Park, Z. Ounaies, K.A. Watson, K. Pawlowski, S.E. Lowther, } \\
\text { J.W. Connell, E..J. Siochi, J.S. Harrison, and T.L. St. Clair }\end{array}$} & \\
\hline \multicolumn{3}{|c|}{$\begin{array}{l}\text { 7. PERFORMING ORGANIZATION NAME(S) AND ADDRESS(ES) } \\
\text { ICASE } \\
\text { Mail Stop } 132 \mathrm{C} \\
\text { NASA Langley Research Center } \\
\text { Hampton. VA } 23681-2199\end{array}$} & $\begin{array}{l}\text { 8. PERFORMING ORGANIZATION } \\
\text { REPORT NUMBER } \\
\text { ICASE RepOrT No. } 2002-36\end{array}$ \\
\hline \multicolumn{3}{|c|}{$\begin{array}{l}\text { 9. SPONSORING/MONITORING AGENCY NAME(S) AND ADDRESS(ES) } \\
\text { Sational Aeronautics and Space Administration } \\
\text { Langley Research Center } \\
\text { Hampton, VA } 23681-2199\end{array}$} & $\begin{array}{l}\text { 10. SPONSORING/MONITORING } \\
\text { AGENCY REPORT NUMBER } \\
\text { NASA/CR-2002-211940 } \\
\text { ICASE Report No. } 2002-36\end{array}$ \\
\hline
\end{tabular}

Langley Technical Monitor: Demis M. Bushnell

Final Report

Submitted to MRS 2001 Fall Proceedings.

12a. DISTRIBUTION/AVAILABILITY STATEMENT

Unclassified-Unlimited

Subject Category 34

Distribution: Nonstandard

Availability: NASA-CASI (301) 621-0390

13. ABSTRACT (Maximum 200 words)

Polymer-single wall carbon nanotube (SWNT) composite films were prepared and characterized as part of an effort to develop polymeric materials with improved combinations of properties for potential use on future spacecraft. Next generation spacecraft will require ultra-lightweight materials that possess specific and unique combinations of properties such as radiation and atomic oxygen resistance, low solar absorptivity, high thermal emissitivity, electrical conductivity, tear resistance, ability to be folded and seamed, and good mechanical properties. The objective of this work is to incorporate sufficient electrical conductivity into space durable polyimides to mitigate static charge build-up. The challenge is to obtain this level of conductivity $\left(10^{-8} \mathrm{~S} / \mathrm{cm}\right)$ without degrading other properties of importance, particularly optical transparency. Several different approaches were attempted to fully disperse the SWNTs into the polymer matrix. These included high shear mixing, sonication, and synthesizing the polymers in the presence of pre-dispersed SWNTs. Acceptable levels of conductivity were obtained at loading levels less than one tenth weight percent SWNT without significantly sacrificing optical properties. Characterization of the nanocomposite films and the effect of SWNT concentration and dispersion on the conductivity, solar absorptivity, thermal emissivity, mechanical and thermal properties were discussed. Fibers and non-woven porous mats of SWNT reinforced polymer nanocomposite were produced using electrospinning.

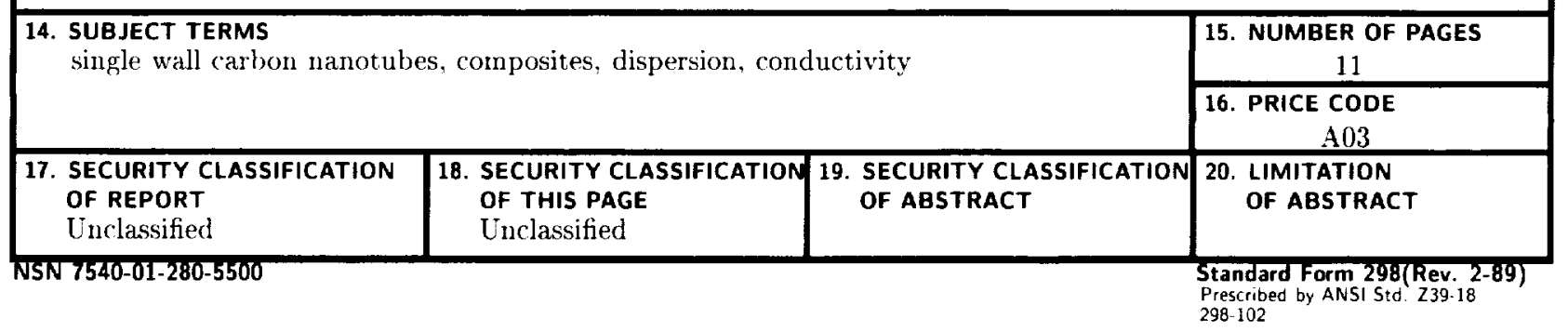

